\title{
Articles
}

\section{Evaluating the Effectiveness and Functionality of Professional Learning Communities in Adult ESL Programs}

\author{
Marilyn L. Abbott, Kent K. Lee, \& Marian J. Rossiter
}

In this article, we describe and evaluate a research utilization initiative designed to bridge the teaching English as a second language (TESL) research-practice gap by fostering the formation of and supporting professional learning communities (PLCS) in adult ESL instructional contexts. We review literature on teachers' professional reading, learning, and development. We use Guskey's (2014) professional learning evaluation framework and Hord's (2009) six critical dimensions of PLCs to assess the effectiveness and functionality of PLCs in nine adult ESL programs. Five years of data collection included focus group interviews, professional learning community discussions, monthly online surveys, and a final follow-up survey. Data were analyzed in relation to (a) the five levels in Guskey's framework: participants' reactions, participants' learning, organization support and change, participants' use of new knowledge and skills, and student learning outcomes; and (b) the functionality of the PLCs. Results indicate that researchersupported PLCS can be effective in assisting teachers to address their professional development needs and goals. However, the interest and enjoyment experienced by participating in the PLCs, and ultimately the sustainability of the PLCs, also depend on the groups' social and professional capital. We provide suggestions for future research and for the creation and maintenance of PLCS in TESL.

Dans cet article, nous décrivons et évaluons une initiative de recours à la recherche conçue pour faire le pont entre la recherche et la pratique dans l'enseignement de l'anglais langue seconde (TESL) en favorisant la formation et le soutien des communautés d'apprentissage professionnelles (CAP) dans des contextes d'enseignement de l'anglais langue seconde (ESL) aux adultes. Nous étudions la documentation sur les habitudes de lecture, l'apprentissage et le perfectionnement des enseignants. Nous utilisons le modèle d'évaluation de la formation continue de Guskey (2014) et les six dimensions critiques des CAP afin d'évaluer l'efficacité et la fonctionnalité des CAP de Hord (2009) dans neuf programmes d'enseignement de l'anglais langue seconde aux adultes. Recueillies sur une période de cinq ans, les données de l'étude proviennent d'entrevues réalisées au sein de groupes de discussion, de discussions au sein de CAP, de sondages mensuels en ligne et d'un sondage de suivi final. Les données ont été analysées en relation avec (a) les cinq 
niveaux du modèle de Guskey (2014): la réaction des participants, l'apprentissage des enseignants, le soutien organisationnel face au changement, l'utilisation par les enseignants des nouvelles connaissances et habiletés et les résultats au niveau des élèves; et (b) la fonctionnalité des CAP. Les résultats indiquent que les CAP appuyées par des chercheurs peuvent aider efficacement les enseignants à subvenir à leurs besoins et à atteindre leurs objectifs en matière de perfectionnement professionnel. Il faut toutefois signaler que l'intérêt et l'appréciation des participants d'une CAP et, en bout de ligne, la durabilité d'une CAP dépendent également $d u$ capital social et professionnel du groupe. Nous faisons des suggestions pour de futures recherches ainsi que pour la création et le maintien de CAP dans le domaine de l'enseignement de l'anglais langue seconde.

KEYWORDS: in-service teacher development, professional learning and development, collaborative research utilization, communities of practice, teaching English as a second language

\section{Introduction}

Professional learning and development activities that positively impact teacher quality (i.e., teacher knowledge, skills, and attitudes) and promote the implementation of research-informed teaching practices have been linked to increases in student learning (Cook, Smith, \& Tankersley, 2012; DarlingHammond \& Richardson, 2009). Both informal learning and formal professional development (PD) initiatives are key mechanisms for translating research into improved practice. Although engagement with current research is a valuable component of professional learning and development, even with increased access to research findings via the Internet, "the emphasis remains on disseminating research without any systematic approach to maximizing teachers' engagement with it" (Borg, 2013, p. 85). If teachers participate in professional learning communities (PLCs) that value research and, therefore, read relevant peer-reviewed research articles, they will have opportunities to discuss and adapt new ideas, materials, and instructional approaches to suit their teaching contexts. Enhanced teacher quality from reading and discussing research in collaborative PLCs potentially positively impacts curricula, instruction, assessment, and education policies. Despite the capacity of PLCs to increase research knowledge utilization, very little is known about the features of PLCs that promote the uptake of peer-reviewed research and contribute to effective adult English as a second language (ESL) instruction and programs. To bridge this research-practice gap and systematically promote the uptake of research, we facilitated the creation of, supported, and evaluated PLCs in nine distinct adult ESL programs in a Canadian city over 5 years. The evaluation of professional learning initiatives in education ensures that the initiatives are producing the intended results: that progress is 
being made toward improving teaching and learning. Two frameworks that outline key standards for evaluating such initiatives are found in Guskey (2014) and Hord (2009). In this article, we examine the effectiveness of the PLCs vis-à-vis Guskey's (2014) professional learning evaluation framework, in terms of the PLC members' reactions, learning, and use of new knowledge and skills; their students' learning; and their organizations' support of the PLCs and organizational changes resulting from the PLCs. We then consider the functionality of the effective PLCs in relation to Hord's (2009) six dimensions of PLCs, thereby integrating the two frameworks.

\section{Literature Review}

In this section, we (a) discuss relevant research on teachers' professional reading, (b) describe the impact of adult ESL teaching contexts on PD, and (c) examine continued professional learning and development in the field of teaching ESL (TESL). We situate our research in the literature on communities of practice (Wenger, 1998; Wenger-Trayner \& Wenger-Trayner, 2015) and outline the key features of PLCs (Hord, 2009). We then provide an overview of the professional learning evaluation framework (Guskey, 2014) that was used to assess the effectiveness of the TESL PLC research utilization initiative described in this article.

\section{Teachers' Professional Reading}

Continued learning from ongoing professional reading should play a key role in informing teachers' decisions and actions in the classroom. Due to the proliferation of information of varying quality on the Internet, trustworthy, peer-reviewed academic research is of increasing value for practitioners. Research has identified time and access as key factors that limit teachers' professional reading (e.g., Abbott, Lee, \& Rossiter, 2017; Abbott, Rossiter, \& Hatami, 2015; Borg, 2007, 2009, 2013; Borg \& Liu, 2013; McDonough \& McDonough, 1990; Nassaji, 2012; Sá, Li, \& Faubert, 2011). Despite initiatives to reduce barriers to professional reading (e.g., by increasing the number of open access journals), the utilization of research in both educational policy and practice is generally limited (Cooper \& Levin, 2010; Lysenko, Abrami, Bernard, Dagenais, \& Janosz, 2014). The lack of research utilization may also be attributed to a perceived disconnect between research and practice. For example, Tavakoli (2015) interviewed $20 \mathrm{ESL} /$ English as a foreign language (EFL) teachers regarding their "views on the relationship between teaching and research" (p. 41). Her findings suggested that the teachers perceived research and teaching as distinct pursuits.

Although several studies of teachers' perceptions of language teaching research have been conducted (e.g., Bartels, 2003; Borg, 2007; Borg \& Liu, 2013; Kamiya \& Loewen, 2014; Mady, 2012, 2013; McDonough \& McDonough, 
1990; Nassaji, 2012; Tavakoli \& Howard, 2012; Tavakoli, 2015), the data gathered in these studies were from single points in time. Allison and Carey (2007) and Tavakoli and Howard (2012) were the only researchers who examined ESL teachers' perceptions of applied linguistics research; all other studies of adult English language teacher research engagement have been conducted in EFL programs or in combined second/foreign language settings (e.g., Borg, 2007, 2009; Borg \& Liu, 2013; McDonough \& McDonough, 1990; Nassaji, 2012; Tavakoli, 2015; TESOL Research Standing Committee, 2008). None of these studies, however, examined research utilization in PLCs and its impact on teacher quality, instruction, and/or student learning over time.

Previous studies of ESL and EFL language teachers' research engagement were also limited by the use of questionnaires with few questions (e.g., Allison \& Carey, 2007), small samples (e.g., Allison \& Carey, 2007; Tavakoli, 2015), and unclear or very limited response options (e.g., Tavakoli \& Howard, 2012). Moreover, these studies dealt primarily with teachers' perceptions of research and did not specifically explore the impact of information found in peer-reviewed journal articles.

\section{Adult ESL Teaching Contexts}

Because research is utilized by different audiences in varying ways (Levin, 2011) and professional learning is shaped by the teaching context (Timperley, 2008), a comprehensive examination of the effectiveness of PLCs must take context into account. Adult ESL instructional contexts in Canada are extremely diverse, ranging from programs that serve refugees with no English and no formal schooling to those that attract international visa students with advanced academic language proficiency (Abbott, Rossiter, \& Hatami, 2015). ESL instructors have varied TESL training and experience (from none to $\mathrm{PhDs}$ ) and teach students across a range of ESL proficiency levels (from beginner to advanced) in a variety of ESL programs (from informal settlement to academic or occupation-specific English language training). Some ESL programs rely on untrained volunteer instructors, while others require instructors with a master's or doctorate in TESL or a related field (Abbott \& Rossiter, 2011). Adult ESL instructors with limited teaching experience or TESL education or training may recognize the need for extensive professional learning and development to meet the complex, ever-changing needs of the ESL learners in their classes (Abbott \& Rossiter, 2011; Abbott, Rossiter, \& Hatami, 2015). Therefore, to reflect the multiple TESL contexts and the diversity of TESL instructor expertise, PLCs were examined in nine distinct private and public adult ESL programs (newcomer/settlement, general ESL, and English for academic purposes) in the research utilization study described in this article. 


\section{Professional Learning and Development in TESL}

Despite their needs for ongoing professional learning and development, many adult ESL instructors are unable to take advantage of costly formal PD opportunities, such as TESL conferences or postgraduate coursework (Abbott \& Rossiter, 2011). When compared with TESL PD in the kindergarten to grade 12 (K-12) system, the PD opportunities afforded adult ESL instructors tend to be quite different (Abbott, Lee, \& Rossiter, 2017). In K-12 education, much time, attention, and funding are devoted to the development of formal PD activities delivered at annual teachers' conventions and during PD days that teachers are paid to attend, and the convention/PD fees are typically covered by their association dues or their school jurisdiction. In contrast, in the context of adult ESL education, many instructors are hired on casual contracts that do not include a PD allowance; therefore, these instructors must fund their own PD activities, and they do not attend them on paid time (Abbott \& Rossiter, 2011). In light of institutional budget restraints or recent funding cuts to PD for instructors in, for example, government-sponsored Language Instruction for Newcomers to Canada (LINC) programs, even instructors with permanent contracts have reduced PD funding. Therefore, alternate cost-effective forms of professional self-development need to be explored. One such form of PD in which teachers can participate is a PLC, where members come together to critically reflect upon, discuss, and apply relevant peer-reviewed research to ESL classroom teaching and learning.

\section{Professional Learning Communities}

In their review of related research on teacher professional learning and development, Darling-Hammond and Richardson (2009) concluded that sustained, collaborative, collegial interactions are important features of high-quality PD. These features are inherent in "communities of practice" (Wenger, 1998), defined as "groups of people who share a concern or passion for something they do and learn how to do it better as they interact regularly" (WengerTrayner \& Wenger-Trayner, 2015, para. 4). Communities of practice are grounded in social constructivism (Vygotsky, 1978), which suggests that knowledge is constructed collaboratively and that learning occurs through negotiated interactions in social communities and contexts. Thus, key features of communities of practice are the sharing of ideas and resources, and the learning that occurs in a supportive social network.

PLCs may be viewed as one type of community of practice in which teachers form trusting relationships while they "learn deeply with colleagues about an identified topic, to develop shared meaning, and identify shared purposes related to the topic" (Hord, 2009, p. 41). The six research-based dimensions of PLCs identified by Hord (2009) include a shared vision/purpose, shared leadership, supportive structural conditions (time, place, resources), supportive relational conditions (respect, caring, trust), collective learning to improve 
teaching and learning, and "individual and organizational improvement" (p. 2).

In PLCs, attention is paid to researching and learning about ways to address students' needs by incorporating new knowledge, teaching approaches, and strategies to enhance instructional effectiveness. PLCs present ongoing opportunities for less structured, informal, interactive forums for research dissemination when compared with one-off, more highly structured, formal, discrete approaches, such as lectures. In PLCs, members can discuss the information found in journal articles, evaluate the utility of new ideas, and consider if/how these could be applied in the workplace. The value of extended practitioner engagement with theory and research in communities of practice lies in their potential to increase adult ESL instructors' knowledge and skills through discussion, review, and knowledge-making (i.e., using the literature to solve problems), not just in reading to validate or verify teachers' current practices, knowledge, or understanding. According to the literature on school-based professional development, although the sustainability of PLCs depends on strong school support and individual commitment (Mak \& Pun, 2015), they have the potential to enhance staff capacity (McLaughlin \& Talbert, 2006). In their review of the research on PLCs, Vescio, Ross, and Adams (2008) concluded that "student learning increases when teachers participate in PLCs" (p. 87). It may, therefore, be assumed that the skillful reading and interpretation of research to address ESL program needs, in supportive learning communities, can lead TESL educators to confirm, rethink, and/or modify their practice to foster effective student and organizational outcomes. This assumption is evaluated in the TESL PLC research utilization initiative reported in this article, using Guskey's (2014) professional learning evaluation framework.

\section{Evaluating Professional Learning}

Guskey (2014) recommends evaluating professional learning by collecting and analyzing information on five successive levels: participants' reactions, participants' learning, organization support and change, participants' use of new knowledge and skills, and student learning outcomes, where success at the higher levels typically depends on success at the lower levels (see Table 1).

Table 1

Guskey's (2014) Professional Learning Evaluation Framework

\begin{tabular}{ll}
\hline Evaluation Level & Criteria \\
\hline 5 & Student Learning Outcomes \\
4 & Participants' Use of New Knowledge \\
3 & Organization Support \& Change \\
2 & Participants' Learning \\
1 & Participants' Reactions \\
\hline
\end{tabular}

Source. Adapted from Guskey (2014), pp. 1222-1224. 
Level 1 involves an examination of the participants' reactions to and the types of experiences they have when participating in the PLCs. This includes their level of participation and enjoyment, their perceptions of the length and frequency of meetings, and the extent to which they believe that their time was well spent. Level 2 includes an exploration of what the participants learned as a result of their participation in the PLCs, in terms of their understanding of theories, concepts, principles, and procedures. "At Level 3 the focus shifts from the participants to organizational dimensions that may be vital to the success of the professional learning experience" (Guskey, 2014, p. 1226), such as organizational supports and characteristics, and institutional or program requirements that may hinder change efforts at the next level. Level 4 is comprised of an examination of the participants' use of the new knowledge and skills gleaned from the PLCs in terms of their effects on the participants' professional practice. Finally, Level 5 involves an investigation of the impact of the PLCs on the students. The key question addressed here is to what extent the PLCs benefitted the students.

\section{Researchers' Positioning and the Current Study}

As applied linguists, TESL faculty, and teacher educators, we are committed to identifying ways to bridge the gap between research and practice in a variety of TESL contexts. Our research is aligned with the belief that reality is constructed through individuals' making meaning within their social world and that we, as researchers, are tools for data collection and analysis (Merriam, 1998). Subjective meaning is developed through analyses conducted in multiple contexts (Magolda \& Weems, 2002), which has led us to value qualitative research methodologies such as applied thematic analysis (Guest, MacQueen, \& Namey, 2012) and their capacity to explore research utilization in TESL PLCs from the diverse perspectives of ESL practitioners (both instructors and administrators). PD initiatives that foster and develop learning communities in which the members consult current research to meet their professional learning needs are examples of approaches that have the potential to bridge the research-practice gap. Because the effectiveness of TESL PLCs had not yet been examined, this study was designed to facilitate and gain an understanding of research utilization in nine diverse adult ESL programs. We did so by supporting, observing, and evaluating the effectiveness of PLCs over a period of 5 years. From this evaluation, we aimed to derive insights regarding the creation and maintenance of effective TESL learning communities. The following research questions guided our evaluation:

Research Question 1 (RQ1): What were the participants' reactions to and experiences in the PLCs?

Research Question 2 (RQ2): What did the participants learn through their participation in the PLCs? 
Research Question 3 (RQ3): What impact did ESL instructor participation in the PLCs have on (a) the supports they received and (b) the organizational changes that occurred?

Research Question 4 (RQ4): How did the ESL instructors use the new knowledge and skills gleaned from the PLCs?

Research Question 5 (RQ5): How did the PLCs benefit the participants' students' learning outcomes?

Research Question 6 (RQ6): How do effective PLCs manifest the six dimensions of PLCs identified by Hord (2009): shared purpose, shared leadership, supportive conditions, supportive relationships, collective learning, and individual and organizational improvement?

\section{Method}

\section{Participants}

A total of 76 instructors of adult ESL students participated in this study. These instructors taught in nine diverse ESL contexts: newcomer settlement language programs $(n=5)$, general ESL programs $(n=3)$, English for academic purposes programs $(n=1)$. Most $(45 \%)$ of the instructors held a master's degree, $27 \%$ a bachelor's, $11 \%$ an after-degree diploma, $7 \%$ an afterdegree certificate, $2 \%$ a $\mathrm{PhD}$, and $2 \%$ a certificate; the remaining $6 \%$ did not state their level of education. In total, $65 \%$ of all participants had specialized in TESL or a TESL-related field such as applied linguistics or second language acquisition. In addition, 30\% held degrees in elementary or secondary education. The others reported degrees/specializations in English literature, linguistics, religious education, special education, early childhood education, history, humanities, and adult education. Participants' adult ESL teaching experience ranged from less than 1 to 21 years; however, the median and mode were 5 and 10 years of full-time teaching experience, respectively.

\section{Procedures}

After receiving ethics approval from multiple institutions, we contacted program administrators at 11 public/private adult ESL programs to request their participation and permission to recruit a minimum of six ESL instructors who were interested in joining colleagues to form a PLC in their program. We asked the participating program administrators to forward our information letter/consent form to their instructors with a request that interested instructors contact us directly.

Instructors from nine programs responded to our invitation without the promise of any financial incentives from either their programs or the research 
team. Once we had received a minimum of six responses from each program, we scheduled an initial meeting with those individuals to provide background information and answer any questions regarding the study. Nine programs met this minimum criterion, one program did not respond, and the other had only two teachers interested in participating in this project. Based on our previous research (Abbott, Rossiter, \& Hatami, 2015; Rossiter, Abbott, \& Hatami, 2013), we provided suggestions for organizing the first PLC discussion. We encouraged the incorporation of a social dimension in all meetings, requested that the participants identify their professional learning needs, and asked that a facilitator be selected to forward monthly, ongoing requests for research articles to address those needs. In response to PLC requests, the research team searched academic databases for articles that accommodated the backgrounds and experiences of the members in each PLC. The references and summaries were forwarded to the facilitators, who shared them with the members. The group members were then asked to choose one research article for monthly discussion. Therefore, each PLC read different articles on a variety of different topics, such as literacy, trauma, assessment, and academic writing. Further suggestions for readings were provided in a column, published four times a year, in a provincial TESL Newsletter.

\section{Data Collection}

Participants in the PLCs were asked to complete an initial online background questionnaire soliciting information on their current program, teaching experience, ESL courses and proficiency levels taught, educational background (and TESL specializations), perceptions of the value of research, and number of research articles read in full within the past year. Each month, the PLC members were e-mailed a link to a cloud-based questionnaire about their group discussions and research utilization (see Appendix A). We conducted 15 focus group interviews (see Appendix B) with the PLCs to inquire about the impact of their learning on their practice (six long-term PLCs were interviewed twice; three more recently created PLCs were interviewed once). Each focus group was approximately $1 \mathrm{hr}$ in length. We also recorded three PLC group discussions to identify how members organized their discussions and interpreted the research. In addition, we conducted three focus group interviews with the PLCs' program administrators to identify the administrators' roles in supporting the groups and their views regarding how the PLCs were benefitting the instructors and learners in their adult ESL programs. The collection of data from multiple sources (instructors, administrators) and methods (surveys, focus group interviews) represented a pragmatic way to address the research objectives. 


\section{Data Analysis}

The quantitative background questionnaire data were downloaded from SurveyMonkey and analyzed using Statistical Package for Social Sciences (SPSS). Frequencies and descriptive statistics for the quantitative demographic survey items (multiple-choice, numeric responses) were calculated. The focus group interviews and PLC recordings were transcribed and verified for accuracy. Open-ended survey data and focus group interviews were analyzed using applied thematic analysis (Guest, MacQueen, \& Namey, 2012), a rigorous, iterative, inductive process that can be used to address real-world issues such as the effectiveness of the PLCs. Participants' responses to the online and focus group questions were read carefully by the researchers to develop familiarity with the data. Then, to understand the depth of the information in relation to each of the levels in Guskey's (2014) framework, the data were reread several times; salient themes related to each level were identified in each reading; themes were refined, discussed among the researchers, finalized, transformed into codes, confirmed in the other participants' responses, and verified for coding accuracy. The researchers resolved the few coding differences through discussion. This procedure helped to establish direct correspondences between the participants' responses and the themes related to each level in Guskey's professional learning evaluation framework. Then, we calculated the percentage of codes assigned to each theme. Finally, Hord's (2009) dimensions of effective PLCs were explored in these data using the iterative analytic procedures described above.

\section{Results and Discussion}

The findings from this study provide insights into the characteristics of TESL PLCs that effectively utilize the information in peer-reviewed research articles. A number of common themes emerged from the multiple sources of data that we collected. These are discussed below in relation to our six research questions.

Evaluating the Effectiveness of the PLCs Using Guskey's (2014) Framework

RQ1: What were the participants' reactions to and experiences in the PLCs? Level 1 (Participants' Reactions) in Guskey's (2014) framework received the greatest number of codes $(40 \%)$ in our analysis of the openended questionnaire and focus group data. Three themes emerged from the codes reflecting participant's reactions, which we labeled as participants' enjoyment, satisfaction with logistics, and perceived value of the PLCs.

Enjoyment. Representative comments from participants that reflect their enjoyment of the PLCs include the following: "I really like the collegial discussion with my peers, to get ideas and bounce them off people" and "The 
readings and discussions provide amazing PD." Over time, the members increased their professional respect for each other as they developed familiarity with one another on a personal level. This sense of respect, which led to greater enjoyment in the PLCs, is evidenced in the following quote from another instructor:

I found that I really developed a deeper respect for my colleagues when I heard how they're using these ideas in their classrooms. Even though you work with these people ... we don't really get that chance to connect on a deeper level with our colleagues. So that was a huge benefit for our group.

The increased comfort that the instructors developed with one another led to greater enjoyment and more open sharing of their opinions, experiences, and resources. One instructor stated, "We have shared so many things." The PLCs with a social component (meeting at a popular diner for breakfast, or at a local pub or restaurant for a drink and snacks after work) appeared to provide the most enjoyable, relaxed interactions - as one instructor commented, "[because] our meetings were in a bar, I really enjoyed the social part." Four members of three different groups, despite moving to new institutions, continued to meet with their original PLCs because they appreciated meeting with the instructors who were now close friends as a result of their involvement in the PLCs. One of these instructors reported, "I love this group." Although the instructors tended to enjoy reading most of the articles, their enjoyment varied from time to time, depending on the articles' practicality, relevance, and accessibility (both availability and ease of understanding). A representative negative comment about particular statistics-laden articles was "It was a very dry read." However, the most frequent comment about the readings was "I enjoyed reading this article."

Logistics. PLC organizational procedures also influenced the participants' reactions and ultimately the effectiveness of the PLC meetings. These procedures included having a regular meeting time, location, and established meeting routines, such as selecting a leader in advance. As one participant suggested,

... having the [discussion] leader is always good because you need to have someone to keep us focused, start the topic and make sure the conversation gets going and you need someone like [name of participant] to be the contact and get things organized.

Favourable logistics were also linked to having a core group of regular members; however, some PLCs experienced more challenges than others in maintaining a stable membership due to the nature of their contract-based employment. As one instructor reported, "Our program has huge number of staff from September to December and then a really low number from January to April. So it's really hard for the group to stay together during 
the off-term." PLC members with high levels of social and professional capital were also fundamental to enhancing PLC membership and functionality: group facilitators and discussion leaders with social capital have good relationships with others, and those with professional capital have the knowledge, skills, and experience to mentor others. Several instructors commented on the facilitation skills of particular group members. Comments about group leaders included, "She was always very well prepared" and "She did a very nice job to get us all in line."

Value. Instructors valued their participation in the PLCs, where they shared their understanding of the readings and how they related to their programs, and the group discussions stimulated reflection and sharing of perspectives and experiences. Representative quotes that reflect the value of the PLCs include the following:

I find this reading group very valuable ... it helps us to build a community.

We come together and we have this core group that reads and shares ideas and shifts our thinking.

To learn from each other is so valuable in a non-threatening, noncompetitive, non-judgmental kind of way.

What I like the most is we always discuss how helpful it [the information in the article] would be and how valuable it would be for our practice.

Another group even referred to their PLC as a form of "free university."

Information in the peer-reviewed articles was also valued, as it often confirmed the participants' instructional practice. A representative comment was "It confirms what I'm doing so I feel good, right?" Many instructors particularly valued classroom-based research that was conducted in contexts similar to their own due to the ease of transfer of the research participants' experiences and practices to their own classes. A typical response to the classroombased research articles was "it was practical."

Overall, the ESL instructors' reactions to participating in the PLCs were overwhelmingly positive, as they enjoyed and valued their participation in the PLCs and were satisfied with the logistics of the professional learning experience.

RQ2: What did the participants learn? Level 2 (Participants' Learning) in Guskey's (2014) framework received the third highest number of codes $(19 \%)$ in our data analysis. We found that the collaborative learning in the PLCs increased the participants' knowledge of theories, principles, concepts, methods, and activities or tasks. For example, one participant stated, "How they learn language ... I became more aware of this process," indicating an 
increased understanding of second language acquisition. Another instructor learned that "It's difficult for learners to encounter vocabulary frequently enough to learn it [incidentally through reading]." Yet another commented, "We learned about the best techniques and strategies [for teaching EAP]."

Participants' learning in the PLCs also contributed to changes in their attitudes. For example, one instructor remarked that she "[started] to look at students from an asset position rather than a deficit position." Another learned that students from different cultures view plagiarism differently than do ESL instructors in North America. She said, "For us, plagiarism is evil, but it's seen differently by students. Some students think it's a compliment to use others' words." Her attitude toward student plagiarism changed as a result. Another instructor stated, "I wasn't on board with TBLT [task-based language teaching] in the beginning ... now I understand [its value]." Participation in the PLCs increased the instructors' abilities to question their practice, as demonstrated by the following quote: "It sure made me reevaluate. I really reevaluated my own [feedback practices]."

Overall, participation in the PLCs increased the instructors' knowledge of second language acquisition and other topics related to TESL. The readings and group discussions were instrumental in helping the instructors increase their breadth and depth of knowledge of a variety of relevant topics. PLC membership had a positive impact on instructors' understanding of their students and classroom practices, and their attitudes toward a variety of topics and issues that related to teaching newcomers. Some participants also improved their ability to locate peer-reviewed articles. The PLCs initially relied on the research team to provide them with peer-reviewed research articles relevant to their expressed professional learning and development needs; over time, however, they became more self-sufficient and found relevant professional learning articles themselves (e.g., using Google Scholar, subscribing to Table of Content alerts from open-access academic journals).

RQ3: What impact did ESL instructor participation in the PLCs have on (a) the supports they received and (b) the organizational changes that occurred? At Level 3 in Guskey's (2014) framework, organizational dimensions that are vital to the success of the professional learning experience are evaluated, including organizational supports/characteristics and institutional or program requirements that have the potential to hinder change efforts at level 4 . A total of $9 \%$ of participants' comments and responses were categorized as Level 3. In our first focus group interview with the ESL program administrators, we learned that institutional supports for the PLCs were extremely limited. Six administrators indicated that the only support they provided was a space to meet at their institution. The other three groups met off campus by choice, at local cafés or restaurants.

Several organizational changes and supports came about as a result of this project. Four of the nine ESL program administrators now recognize PLC involvement on their instructors' annual reports, and these PLCs continue to 
meet; however, the other five PLCs that were provided with meeting space only disbanded either before or shortly after the last monthly questionnaire was sent out. In addition to documenting PLC activity on individual teachers' annual reports, three government-funded settlement ESL programs now document PLC activities in their reports to the federal government as evidence of ongoing professional learning and development in their organization. Another positive example of organizational change and support resulting from this project is that one of the four continuing PLCs now meets during paid PD hours, whereas previously, all PLCs met during unpaid time.

Learnings gained from PLC activities have also led to changes in teaching and student placement evaluations. For example, at one institution, administrators now systematically and critically evaluate teachers' corrective feedback practices using recommendations from the research. One stated, "I use the table [of feedback types] in my teacher evaluations [to provide constructive feedback to teachers during classroom observations]." In another organization, teachers' sensitivity to posttraumatic stress disorder among their refugee population resulted in program-level improvements in evaluation practices. For example, an instructor from one program stated, "We changed an item [referring to a previous frightening experience] on that [placement] test because of our new awareness of refugees." In another instance, an open-ended item on an exit exam was modified to eliminate reference to frightening experiences in learners' pasts.

Although the ESL program administrators in the nine programs provided consent for the PLC initiative before the study began, no other assistance was requested. However, after we asked the administrators in the focus group interviews about the supports they could provide to encourage PLC research engagement, some of them began recognizing their instructors' participation on their annual reports and in reports to funders. Another administrator allowed the PLC to meet during paid PD time, and this PLC continues to meet. Evidently, organizational support beyond what the researchers offered (i.e., tips on how to organize a group and assistance in locating relevant articles) is a key factor in PLC sustainability.

Instructors' participation in the PLCs also promoted specific improvements in institutional policies and practices within their ESL programs. Among these were changes in observations for teacher evaluation and student assessment practices; both types of improvements were based on knowledge gained from the articles that the groups had read and discussed.

Although participants' learnings (Level 2 in Guskey, [2014]) led to positive outcomes in organizational change and support at Level 3, we also found that existing program funder requirements prohibited some changes. For example, in LINC programs, teachers must use task-based language teaching and portfolio-based language assessment, leaving little time for other forms of assessment. As Guskey (2014) suggests, it is important, therefore, to consider the influence of Level 3 on Level 4 outcomes. In our study, the instruc- 
tors implemented new ideas and research-informed practices where possible, given the constraints of the institutions in which they worked.

RQ4: How did the ESL instructors use the new knowledge and skills gleaned from the PLCs? Level 4 (Participants' Use of New Knowledge and Skills) in Guskey's (2014) framework received the second highest number of codes $(25 \%)$ in our data analysis. It addresses the question, "Did the new knowledge and skills that participants learned make a difference in their professional practice?" (Guskey, 2014, p. 1227). Participation in our study required teachers to be reflective in their practices, as we asked them to report what they had learned and applied in the classroom in the focus group interviews and monthly questionnaires. Teachers also shared their classroom experiences and practices in their PLCs. A few instructors volunteered to keep a journal documenting how they applied new knowledge, and these were used to provide input during the data collection. Reflection and discussion promoted the implementation of new ideas or changes in instructional practices.

The following quotes reflect some of the participants' gains in knowledge and skills, and changes in their practice:

I now provide specific instruction in paraphrasing and more practice in summarizing and using appropriate citations [rather than reporting students for plagiarism].

I started designing my lessons based on explicit teaching of vocabulary focusing on teaching formulaic sequences.

Reading this article actually helped me identify my learners' [pronunciation] needs better.

After reading this, I started using stories in the classroom.

Now I have students keep a reading log.

Participation in the PLCs provided teachers with increased confidence in applying new ideas in their instructional practices. As one instructor confirmed, "When you take [these new practices] to class, you're more confident."

The PLC participants were interested in becoming better practitioners, so they took the initiative to read, reflect, meet, and discuss their own learning and teaching practices. Initially, the participants viewed their groups as book clubs, in that the focus was on what they had read. As the study progressed, however, the groups transitioned to a focus on applying information from the articles to improve their instruction and students' learning outcomes.

At times, it was difficult for a few of the instructors to apply the information in the articles to their practice. This lack of transfer may be partially 
attributed to the fact that applied linguistics researchers are often hesitant to identify potential implications of their research for practice in their articles. They acknowledge that the implications of their research may not be appropriate for all teaching contexts, given the complexities of language learning and the interactions between individual differences (e.g., age, motivation, education level, first language and literacy, target language proficiency level, exposure to the target language). However, it is important to note that the effective PLCs did not view the reading of research as merely the transfer of information. Rather, they teased out the valuable elements contained in the methods (interventions and materials used) and findings (taxonomies, word lists, etc.) of the articles, and adopted or adapted these, where possible, for their own professional teaching contexts. They were actively engaged in critiquing the research, making connections between the findings and their contextual knowledge, and then using any information from the article they deemed valuable and appropriate for making research-informed decisions. They also reflected on the intended and potentially unintended consequences of those decisions on their practice. Effective groups also integrated their learning from previous readings into subsequent discussions.

The PLC members structured their learning environments to utilize collective knowledge gained through group interactions to achieve practical learning goals, to solve problems, and to facilitate change. The new knowledge and skills that they gained from the readings and discussions were reported to enhance the PLC instructors' confidence and professional practices. The degree of knowledge utilization (i.e., outcomes of reading the articles) in terms of supporting teaching and learning, however, varied from one context to another. The impact of research on practice was sometimes influenced by the extent to which the instructors had opportunities to use the ideas presented in the articles read. For example, if a particular group read an article on EAP writing instruction but one instructor in the group was teaching a beginner listening and speaking class at the time, there were limited opportunities for that instructor to transfer the implications of the writing research to her classroom instruction. Some individuals and PLCs were better than others at seeing the value of the various components/elements of the research articles and making connections between the research and their practice, depending on their TESL education and teaching experiences. In one PLC, for instance, the reading of academic research articles was found to be problematic for those readers who did not have any previous experience reading academic journal articles. In all other cases, however, discussion and cooperative learning promoted deeper understanding of the research for all participants.

RQ5: How did the PLCs benefit the participants' students' learning outcomes? Level 5 (Student Learning Outcomes) in Guskey's (2014) framework addresses the question, "Did the [PLC] benefit the students in any way?" (p. 1228). A total of $7 \%$ of the participants' comments and responses 
reflected benefits to students. Instructors shared evidence-based strategies and research-informed practices with their students that were gleaned from their readings and PLC discussions. These practices are reflected in the following comments:

I showed them the stats [listening fluency and vocabulary gains from reading while listening]. When they saw the stats, how much it increased, that motivated them.

When [practices] are researched-based and when you talk about it in class, it's stronger.

Students, in turn, acknowledged the validity of their teachers' actions. As one instructor stated, "students felt more comfortable to know that certain ideas are research-based."

The following quotes provide additional examples of some of the ways in which students benefitted from this initiative:

Students have increased their computer proficiency.

Since our discussion of cultural differences, and differences in communication styles, I have seen evidence of heightened respect for each other's point of view, and the growing ability to truly listen and respond to each other's opinion.

The students have greater awareness of trends in language learning and difficulties that other students face.

They understand what is meant by plagiarizing.

These quotes suggest that the PLCs positively impacted the students' performance, attitudes, skills, and behaviours.

The positive outcomes across Levels 1 to 4 in Guskey's (2014) framework led to student benefits related to their performance, attitudes, skills, and behaviours at Level 5 . Teachers were able to share their new knowledge with their ESL learners. Instructors reported that students with whom they shared evidence-based learnings gained in motivation and confidence and were able to apply strategies to their own language acquisition. In addition, learners' classroom performance and understandings were reported to benefit from their instructors' participation in the PLCs. Overall, the instructors agreed that their involvement in the PLCs made a difference in the quality of their instruction and that their students responded positively to changes in classroom practices.

Although all of the PLCs were effective in terms of meeting the five criteria in Guskey's (2014) framework, clearly not all of the PLCs were viable in the long term. We are pleased that four of the nine PLCs continue to meet; the 
other five disbanded after our last monthly questionnaire was disseminated. To better understand why the four remaining PLCs continue to thrive, we discuss their success in terms of Hord's (2009) six critical dimensions of PLCs.

Evaluating the Functionality of the PLCs Using Hord's (2014) Dimensions of PLCS

RQ6: How do effective PLCs manifest the six dimensions of PLCs identified by Hord (2009): shared purpose, shared leadership, supportive conditions, supportive relationships, collective learning, and individual and organizational improvement?

Shared vision/purpose. Each PLC read different articles for different purposes. The PLCs coordinated their own professional learning by choosing the topics that met their shared vision/purpose and selecting the articles for their groups to read. Finding a shared purpose was a greater challenge for those PLCs in which members taught a wider range of courses and, therefore, had less homogeneous needs and interests. Members in the continuing PLCs all share common professional learning and development needs.

Shared leadership. The PLC meeting procedures varied from program to program, but most PLCs rotated leadership responsibilities (selecting the article, setting the meeting time, sending out reminders, leading the discussion). In one PLC, however, one individual selected all the articles and served as the discussion leader for 2 full years. Unfortunately, 2 months after she stepped down, the PLC disbanded. Although the PLCs began with strong, committed leaders, the PLCs that continue to flourish are the ones in which all members are willing to share responsibilities for organizing and leading the monthly meetings. The continuing PLCs jointly select the next article and discussion leader at the beginning of each meeting. These results confirm that shared leadership is a critical element of successful PLCs.

Supportive structural conditions. The program administrators of the four ongoing PLCs now offer supports beyond a meeting space. They recognize on participants' annual reports the benefits of PLC involvement and the role they play in instructors' PD. Allowing members to meet during paid PD time is a key support to one continuing PLC. Organizational supports are, therefore, critical for long-term PLC success; the primary reason for PLC disbandment in the other programs appeared to be the lack of supportive structural conditions. Recognition of participation is one type of support that contributes to the success of the ongoing PLCs.

Supportive relational conditions. Our research utilization initiative contributed to supportive, collegial relationships that were developed and strengthened in the PLCs over time. Teachers in the ongoing PLCs are personally connected; they respect, care for, and trust each other. One participant likened her PLC to a teacher support group. Continued PLC membership 
provides opportunities for team building, networking, and enculturating new instructors into the profession.

Collective learning to improve teaching and learning. The opportunity for professional learning through collaborative interactions with inspirational colleagues influenced PLC success. In all the PLC meetings, the teachers collectively contributed to one another's learning by sharing ideas, expertise, and resources. Some PLC members read with greater intensity and thoroughness and were more skilled at interpreting, adapting, and using various aspects of the research in their professional practice. Together, however, by sharing their questions, interpretations, and reactions to the articles, PLC members further developed their understanding of the readings and their potential to improve teaching and learning.

Individual and organizational improvement. Successful PLCs were able to use the information in the peer-reviewed articles to make positive changes in their ESL programs and/or their instruction (knowledge, skills, attitudes, behaviours). By continuing to meet and learn, the members of the ongoing PLCs have greater motivation and opportunities for enhancing individual and organizational effectiveness.

Overall, our findings revealed that the four continuing PLCs were the most effective PLCs, as evidence was found to support each level in Guskey's (2014) professional learning evaluation framework and each of Hord's (2009) six dimensions of PLCs. In the next section, we connect our results to the broader research literature on professional learning and development.

\section{Connections to the Broader Literature on Teacher Professional Learning and Development}

In the context of K-12 education, McLaughlin and Talbert (2006) presented evidence that teacher participation in school-based learning communities leads to enhanced teacher capacity; in adult ESL instructional contexts, our analyses revealed that PLCs have the potential to enhance instructors' capacities to utilize knowledge gleaned from reading and discussing peer-reviewed articles in PLCs. Similar to Vescio et al.'s (2008) conclusion that teacher participation in PLCs increases student learning, the instructors in our study reported positive impacts on their students' learning. We attributed the positive impacts on both instructor and student learning to the success of the PLCs across Levels 1 through 4 in Guskey's framework. Regarding the sustainability of PLCs, our analyses confirmed Mak and Pun's (2015) conclusion that supports and commitment from both the schools and individual participants are vital to PLC longevity. In our study, the ongoing ESL program and institutional recognition that the effective PLCs and their members received, and the commitments individuals demonstrated, not only through their participation in PLC activities but also through their willingness to share leadership responsibilities, ensured that their PLCs were sustainable. These conclusions 
about sustainability are further substantiated by our observations that the PLCs lacking in institutional support and shared leadership disbanded.

In a broader sense, all nine PLCs in our study reflected the key characteristics of communities of practice identified by Wenger-Trayner and WengerTrayner (2015): the instructors met regularly to reflect on and learn about ways to improve their professional practice. The reading of peer-reviewed articles provided the PLCs with a catalyst for discussions with colleagues about teaching and learning that resulted in the co-construction of knowledge (Vygotsky, 1978) in collaborative and collegial environments-hallmarks of both communities of practice (Wenger-Trayner \& Wenger-Trayner, 2015) and high-quality PD (Darling-Hammond \& Richardson, 2009). More important, unlike Tavokoli's (2015) finding that ESL/EFL teachers perceived teaching and research as separate communities of practice, our research indicates that the mobilization of relevant research and collaborative learning that can occur in research-supported PLCs has the potential to connect the two communities and effectively bridge the gap between research and practice.

Although the concept of enjoyment is implied in Hord's (2009) six dimensions of PLCs, we feel that it deserves the distinct status of an essential unique dimension, as positive participant reactions and experiences form the foundation for successful professional learning initiatives (see Level 1 in Guskey, 2014). In our study, we identified enjoyment as a salient reaction that appeared to be connected to the group members' social and professional capital; moreover, the participants' enjoyment in their PLC experiences compensated for the time constraints that have been found to limit teachers' professional reading (e.g., Abbott, Lee, \& Rossiter, 2017; Abbott, Rossiter, \& Hatami, 2015; Borg, 2007, 2009, 2013; Borg \& Liu, 2013; McDonough \& McDonough, 1990; Nassaji, 2012; Sá, Li, \& Faubert, 2011). Despite their busy lives, our participants made deliberate choices to read and meet for their work-related PLCs during unpaid personal time. Therefore, we argue that, in addition to the six dimensions of PLCs identified by Hord (2009), an enjoyable PLC experience is fundamental to sustained PLC participation.

\section{Future Research}

We offer the following recommendations for further research on knowledge mobilization in TESL PLCs. In our analysis, we relied on instructors' perceptions of the impact of PLC membership on students' achievement, skills, behaviours, and affective outcomes; however, future research could be conducted using quantitative measures to assess the impact on actual student achievement. Learner outcome measures could also be examined to evaluate the effect of professional learning on ESL "students' self-concepts, study habits, attendance, homework completion rates ... participation in school-related activities, disciplinary actions, and retention or drop-out rates" (Guskey, 2002, p. 52). In addition, although we collected qualitative perceptions of the 
extent to which the PLCs impacted participants' ESL programs, quantitative data could be gathered from administrators to explore these effects in greater depth. Research is also needed to identify further supports for and to understand the phases of PLCs, including the causes of disbandment.

\section{Conclusion}

The ultimate goal of this longitudinal project was to promote research knowledge mobilization that leads to evidence-informed teaching practices. Earlier research on teachers' professional reading focused primarily on teachers' perceptions of research, but no previous studies examined the impact of PLCs on ESL instructors' research utilization. Our results demonstrate the effectiveness of researcher-supported PLCs in improving instructor quality (knowledge, skills, and attitudes) and promoting organizational change, improved student outcomes, and evidence-informed practice in TESL. Over the course of the study, with researcher encouragement, participants demonstrated the ability to apply the research literature in creative ways. They valued and welcomed new ideas and used their professional judgement to evaluate, choose, adapt, and implement the new ideas and materials they believed would work best to meet the needs of their ESL learners and programs. In other words, the instructors transformed the best practices that were identified in the research literature into what Hargreaves and Fullan (2012) termed "next practices" (p. 50) to accommodate their teaching contexts and to promote efficient, effective learning.

Evidence from our study also suggests that supports from both researchers and ESL program administrators can assist instructors in bridging the gap between research and practice. Researchers, program administrators, and instructors together have the greatest potential for finding innovative ways to support and sustain TESL PLCs. Without systematic researcher and organizational supports, such as program administrator recognition of their benefits, PLCs in adult ESL programs are unlikely to flourish.

Ongoing participation in collaborative TESL PLCs is an effective, costeffective means of engaging in relevant, accessible, contextually appropriate professional learning and development that meet the changing needs in TESL. Guskey's (2014) professional learning evaluation framework and Hord's (2009) six dimensions of PLCs were useful tools for evaluating the outcomes of our research utilization initiative. When combined, these two frameworks provide valuable insights for the creation and maintenance of effective, functional, sustainable PLCs.

\section{Acknowledgements}

We'd like to thank the adult ESL instructors and administrators for participating in this study; the program administrators for providing permission to establish reading groups in their ESL programs; the 
University of Alberta's Faculty of Education, the Killam Research Fund, and the Office of the VicePresident (Research) for their support of this research; and Sarvenaz Hatami and Monica MacFadzean for their assistance with data transcription.

\section{The Authors}

Marilyn L. Abbott is Associate Professor in the TESL program in the Department of Educational Psychology at the University of Alberta.

Kent K. Lee has a PhD in Studies in Teaching and Learning English as a Second Language and is a sessional instructor in the TESL Program in the Department of Educational Psychology and the Department of Secondary Education at the University of Alberta.

Marian J. Rossiter is Professor Emerita in the TESL Program, Department of Educational Psychology, University of Alberta.

\section{References}

Abbott, M. L., \& Rossiter, M. J. (2011). The professional development of rural ESL instructors: Program administrator and instructor views. Alberta Journal of Educational Research, 57(2), 203-218.

Abbott, M. L., Rossiter, M. J., \& Hatami, S. (2015). Promoting engagement with peer-reviewed journal articles in adult ESL programs. TESL Canada Journal, 33(1), 80-105.

Abbott, M. L., Lee, K., \& Rossiter, M. J. (2017). Enhancing the impact of evidence-based publications on K-12 ESL teacher practices. Alberta Journal of Educational Research, 63(2), 193-213.

Allison, D., \& Carey, J. (2007). What do university language teachers say about language teaching research? TESL Canada Journal, 24(2), 61-81. https://doi.org/10.18806/tesl.v24i2.139

Bartels, N. (2003). How teachers and researchers read academic articles. Teaching and Teacher Education, 19(7), 737-753. https://doi.org/10.1016/j.tate.2003.06.001

Borg, S. (2007). Research engagement in English language teaching. Teaching and Teacher Education, 23(5), 731-747. https://doi.org/10.1016/j.tate.2006.03.012

Borg, S. (2009). English language teachers' conceptions of research. Applied Linguistics, 30(3), 358-388. https://doi.org/10.1093/applin/amp007

Borg, S. (2010). Language teacher research engagement. Language Teaching, 43(4), 391-429. https://doi.org/10.1017/S0261444810000170

Borg, S. (2013). Teacher research in language teaching: A critical analysis. Cambridge, UK: Cambridge University Press.

Borg, S., \& Liu, Y. (2013). Chinese college English teachers' research engagement. TESOL Quarterly, 47(2), 270-299. https://doi.org/10.1002/tesq.56

Cook, B. G., Smith, G. J., \& Tankersley, M. (2012). Evidence-based practices in education. In K. R. Harris, S. Graham, \& T. Urdan (Eds.), APA educational psychology handbook, Vol. 1 (pp. 495-528). Washington, DC: American Psychological Association.

Cooper, A., \& Levin, B. (2010). Some Canadian contributions to understanding knowledge mobilization. Evidence \& Policy, 6(3), 35-69. https://doi.org/10.1332/174426410X524839

Darling-Hammond, L., \& Richardson, N. (2009). Teacher learning: What matters? Educational Leadership, 66(5), 46-53. Retrieved from http://www.ascd.org/publications/educationalleadership.aspx

Guest, G., MacQueen, K. M., \& Namey, E. E. (2012). Applied thematic analysis. Thousand Oaks, CA: Sage. 
Guskey, T. R. (2002). Redesigning professional development: Does it make a difference? Educational Leadership, 59(6), 45-51. Retrieved from http://www.ascd.org/publications/educational-leadership.aspx

Guskey, T. R. (2014). Evaluating professional learning. In S. Billett (Ed.), International handbook of research in professional and practice-based learning (pp. 1215-1235). New York, NY: Springer International.

Hargreaves, A., \& Fullan, M. (2012). Professional capital: Transforming teaching in every school. New York, NY: Teachers College Press.

Hord, S. (2009). Professional learning communities: Educators work together toward a shared purpose-improved student learning. Journal of Staff Development, 30(1), 40-43. Retrieved from https://learningforward.org/publications/jsd

Kamiya, N., \& Loewen, S. (2014). The influence of academic articles on an ESL teacher's stated beliefs. Innovation in Language Learning and Teaching, 8(3), 205-218. https://doi.org/10.1080/1 7501229.2013 .800077

Levin, B. (2011). Mobilising research knowledge in education. London Review of Education, 9(1), 15-26. https://doi.org/10.1080/14748460.2011.550431

Lysenko, L. V., Abrami, P. C., Bernard, R. M., Dagenais, C., \& Janosz, M. (2014). Educational research in educational practice: Predictors of use. Canadian Journal of Education, 37(2), 1-26. Retrieved from http://journals.sfu.ca/cje/index.php/cje-rce/article/view/1477/1691

Mady, C. (2012). Second language research and teaching: Bridging the gap. Babel, 47(2), 30-37.

Mady, C. (2013). Reducing the gap between educational research and second language teachers' knowledge. Evidence and Policy, 9(2), 185-206. https://doi.org/10.1332/174426413X662509

Magolda, P., \& Weems, L. (2002). Doing harm: An unintended consequence of qualitative inquiry. Journal of College Student Development, 43, 490-507.

Mak, B., \& Pun, S-H. (2015). Cultivating a teacher community of practice for sustainable professional development: Beyond planned efforts. Teachers and Teaching: Theory and Practice, 21(1), 4-21. https://doi.org/10.1080/13540602.2014.928120

Merriam, S. B. (1998). Qualitative research and case study applications in education. San Francisco, CA: Jossey-Bass.

McLaughlin, M. W., \& Talbert, J. E. (2006). Building school-based teacher learning communities: Professional strategies to improve student achievement. New York, NY: Teachers College Press.

McDonough, J., \& McDonough, S. (1990). What's the use of research? ELT Journal, 44(2), 102-109. https://doi.org/10.1093/elt/44.2.102

Nassaji, H. (2012). The relationship between SLA research and language pedagogy: Teachers' perspectives. Language Teaching Research, 16(3), 337-365. https://doi. org/10.1177\%2F1362168812436903

Rossiter, M. J., Abbott, M. L., \& Hatami, S. (2013). Enhancing the reading of peer-reviewed research in the teaching English as a second language community. Alberta Journal of Educational Research, 59(4), 674-692.

Sá, C., Li, S., \& Faubert, B. (2011). Faculties of education and institutional strategies for knowledge mobilization: An exploratory study. Journal of Higher Education, 61(5), 501-512. https:// doi.org/10.1007/s10734-010-9344-4

Tavakoli, P. (2015). Connecting research and practice in TESOL: A community of practice perspective. RELC Journal, 46(1), 37-52. https://doi.org/10.1177/0033688215572005

Tavakoli, P., \& Howard, M. J. (2012). Teaching English to speakers of other languages teachers' views on the relationship between research and practice. European Journal of Teacher Education, 35(2), 229-242. https://doi.org/10.1080/02619768.2011.643398

TESOL Research Standing Committee. (2008). TESOL members' views of research. Alexandria, VA: TESOL.

Timperley, H. (2008). Teacher professional learning and development. International Academy of Education and International Bureau of Education, Educational Practices Series 18. Geneva, Switzerland: International Bureau of Education Publications Unit. 
Vescio, V., Ross, D., \& Adams, A. (2008). A review of research on the impact of professional learning communities on teaching practice and student learning. Teaching and Teacher Education, 24(1), 80-91. https://doi.org/10.1016/j.tate.2007.01.004

Vygotsky, L. S. (1978). Mind in society: The development of higher psychological processes. Cambridge, MA: Harvard University Press.

Wenger, E. (1998). Communities of practice: Learning, meaning, and identity. Cambridge, UK: Cambridge University Press.

Wenger-Trayner, E., \& Wenger-Trayner, B. (2015, April). Communities of practice: A brief introduction. Retrieved from http://wenger-trayner.com/wp-content/uploads/2015/04/07-

Brief-introduction-to-communities-of-practice.pdf

\section{Appendix A}

\section{Online Monthly Survey}

Last month, your reading group discussed the following article:

Title:

Author:

A1. To what extent has reading the above article impacted your teaching since then?

Please explain.

A2. To what extent has the discussion of this article impacted your teaching since then?

Please explain.

A3. To what extent has the classroom application of the information in the article enhanced your students' learning?

Please explain.

B1. What article was chosen for discussion in this month?

Title:

Author:

B2. To what extent did reading the most recent article impact your teaching?

Please explain.

B3. To what extent did the discussion of this article impact your teaching?

Please explain. 


\section{Appendix B}

\section{Instructor Semistructured Focus Group Interview Guide}

1. Have the articles that you've read over the past few months been engaging and stimulating for you? Was your time well spent? Have you enjoyed being involved in the group? Did the articles make sense? Was the discussion useful?
[Name of article]
Yes $\square \quad$ No
[Name of article]
Yes $\square$ No
Please explain.
[Name of article]
Yes $\square$ No
Please explain.
Please explain.

etc.

2. What have you learned as a result of reading this article? How have you applied the knowledge that you gained from it in your practice? Please provide specific examples. Changes in attitudes, knowledge, skills, and behaviours? Impact on your instruction? Impact on student learning? Impact on your program/organization-changes/supports/recognition?

3. What challenges has involvement in the group had for you?

4. What additional supports could be provided to enhance your group experience?

5. What additional supports could be provided to sustain your group?

6. What are the key elements of a successful group? What characteristics of your group support sustained membership? What will be necessary for the continued success of your group? Please rank them in order of importance.

7. Is there is anything else you'd like to share about your experiences in the group?

\section{Appendix C}

\section{ESL Program Administrator Semistructured Focus Group Interview Guide}

1. Have the PLCs benefitted your program?
$\square$ Yes $\square$ No
Please explain.

2. Has the reading of peer-reviewed research benefitted your ESL instructors and learners?

$\square$ Yes $\square$ No

If yes, what benefits has it had?

3. What supports and strategies did your program provide for sustaining the groups?

4. What could be done to encourage more instructors to be involved in PLCs? 